\title{
Mental Health and its Relationship With Social Support in Iranian Women With High-Risk Sexual Behaviors
}

\author{
Sharare Amani ${ }^{(\mathbb{1}}$, Hossin Ebrahimi $^{2}$, Mojgan Mirghafourvand ${ }^{3}$, Fahimeh Sehhatie Shafaie $^{4^{*}(\mathbb{D})}$
}

\begin{abstract}
Objectives: The violence and prostitution are examples of the stressors in the women with high-risk sexual behaviors and can create a psychological crisis in these women. The purpose of this study was to determine the relationship of mental health with social support in the women with high -risk sexual behaviors visiting drop-in centers (DICs) in Tabriz, Iran, in 2017.

Materials and Methods: This cross-sectional study was conducted on 149 women with high-risk sexual behaviors, visiting three DICs in Tabriz, Iran. The sampling was purposive and non-random. Data were collected using socio-demographic characteristics, social support (PRQ-part 85), and mental health (GHQ-28) questionnaires. A test of multivariate linear regression was performed to identify a number of mental health determinants and explanation of variance.

Results: The mental health score was 50.7 (18.2), the score ranged from 0-84. The best status belonged to depression subscale [10.5 (7.1)] and the worst status belonged to social dysfunction subscale [14.6 (4.5)]. The mental health and its subscales had a significant relationship with social support $(P<0.001, \mathrm{R}=-0.55$ to -0.33$)$. The variables of social support, drug use, and spousal violence were able to predict $35.4 \%$ of mental health variance in the women.

Conclusions: According to the results, appropriate strategies are needed to promote social protection and mental health in the women with high-risk sexual behaviors in order to reduce the sexually transmitted diseases especially HIV/AIDS in the society. Keywords: Women, High-risk sexual behaviors, Mental health, Social support
\end{abstract}

\section{Introduction}

The mental health of female sex workers is affected by violence and sex (1). There is a hypothesis that female prostitutes are subject to trauma and depression due to childhood sexual abuse and are more exposed to high-risk sexual behaviors due to an untreated mental trauma and the inability to adapt to the crisis (2).

Sexual behaviors are considered high-risk when people are not aware of their own health or their sex partner's, and have unsafe sex with a risk of having sexually transmitted infections. The high-risk sexual behaviors or unsafe sex include sexual relations with multiple partners, unprotected sex (sex without a condom), sexual violence, drug or alcohol use in sexual relations, and unusual oral and anal sex $(3,4)$. One of the main outcomes of these behaviors is the risk of HIV, which has the highest mortality rate in association with sexually transmitted infections. Other outcomes include syphilis, chlamydia, gonorrhea, and hepatitis (4).

Women with high-risk sexual behaviors have little support and often suffer from violence, homelessness, and drug addiction. They need attention and support to reduce HIV/AIDS infection and to retrieve their physical and mental health (5).

The World Health Organization (WHO) has defined mental health as "a state of complete physical, psychological, and social well-being and not merely the absence of a disease". It is the promotion and prevention of mental disorders or the treatment and rehabilitation of mental illnesses to such a degree that the person is aware of their potential, can deal with everyday stress, work productively, and be useful to the society (6).

The basic principles of mental health are: respect for oneself and others, knowing the limitations, knowing that human behavior relies on various factors like the existential personality and the needs or factors that affect them for action. WHO has aims for promoting mental health including: preventing mental illness by creating social and psychosocial support systems as well as timely treatment and treatment of mental illness (7).

Mental health has a direct relationship with social support. In a study, depressed people had less perceived social support than healthy ones (8). Appropriate social support can be a contributing factor in empowering the women with high-risk sexual behaviors (9). It has been reported that support from the family or a sexual partner has been effective in quitting addiction in the women with multiple sexual partners $(10,11)$.

Social support is defined as a combination of interpersonal interactions among or assistance provided 
by members of a group or a social network that can reduce the effects of stress on health. Social support has a structural dimension (network size, number of interactions), and a functional dimension (emotional support or financial support) (12). Women seek emotional support more than men, which can be the reason why they seek membership in multiple social networks and get more social support. The social class can also be effective in gaining the social support. People in higher classes are more likely to receive attention and support due to having financial and economic resources (13).

Today, the pattern of HIV/AIDS has changed in sexuality and age. The highest incidence is in the women or young people, and high- risk sexual behaviors are the most common ways of transmission $(14,15)$. Since women make up one half of the societies, any deviation from health status in the women can be a threat to the health of community and future generations. The aim of this study was to obtain useful information about mental health and social support in the women with high-risk sexual behaviors in such a way that we can take effective steps in the prevention of sexually transmitted diseases, promotion of general health and sustainable development goals. The government can support and empower these women on one hand, and decrease the incidence of HIV/ AIDS and sexually transmitted infections in the society, on the other hand.

\section{Materials and Methods}

This cross-sectional study recruited 149 women with high-risk sexual behaviors in Tabriz, Iran, in 2017. The research was conducted at three women's drop-in centers (DICs) (Ibn Sina, Ashrafi Laleh, Shahriar). The goal of these centers is to prevent and reduce high-risk sexual behaviors and reduce the resultant burden of diseases, in particular, to reduce the incidence of HIV/AIDS. The inclusion criteria were the women with health records in DICs that had multiple sex partners and were possibly addict. The exclusion criteria were the women who did not have multiple sex partners.

The sample size was equal to 149 subjects based on the data available in a study by Mirghafourvand et al, considering standard deviation $(\mathrm{SD})=17.6, \quad \alpha=0.05$, Power $=90 \%$, and $\mathrm{d}=0.03$ rounded mean $(\mathrm{m}=134.3)$ and likewise a study by Sahebi et al, considering $\mathrm{SD}=5.6, \mathrm{a}=$ 0.05 , Power $=90 \%$ and $d=0.1$ rounded mean $(m=11.8)$ $(13,16)$.

Sampling was performed purposive and non-random, after obtaining permission from the Ethics Committee of Tabriz University of Medical Sciences. The researcher visited the centers and obtained written informed consent from the eligible and willing women after assessing the women visiting the centers for usual health care services, and then completed the socio-demographic characteristics, social support, and mental health questionnaires through interviews. The questionnaires were encoded in order to keep the information confidential. Some gifts were presented to the participants by the researcher for better cooperation in the interviews.

\section{Data Collection Instruments}

The questions of socio-demographic questionnaire included age range, marital status, occupation and income source, income adequacy, place of residence, history of using a condom, history of drug, alcohol and tobacco use, history of imprisonment, sexually transmitted diseases, violence, and history of sexual abuse by relatives.

The personal resource questionnaire, 85-part 2s, designed by Weinert and Brandetin in 1987, was used for the perceived social support. This questionnaire has 25 items for social support dimensions. The scores of questionnaire are based on the Likert scale and include fully against (1), against (2), somewhat against (3), I don't know (4), agree on (5), slightly agree (6), and fully agree (7). Total score range of questionnaire is from 25 to 175 . The scores are classified into three groups of high (126$175)$, moderate (76-125), and low social support (25-75). The reversal questions are $4,7,10,16$ and 24 , so scoring method of these questions is reverse (17).

The mental health questionnaire is general health questionnaire, designed by Goldberg, and has four scales of anxiety symptoms, depression, social functioning, and physical status, each scale having 7 items. The scoring is based on a Likert scale and ranges between 0-3. A score above 5 is abnormal for each scale and a score above 24 is abnormal for the total questionnaire. The total score for questionnaire is 0 to 84 and for each scale is 0 to 21 . Questions 1-7 relate to the physical status, questions 8-14 to anxiety, questions 15-21 to social functioning, and questions 22-28 to depression. Reversal questions are $1,17,18,19,20$, and 21 and scoring method of these questions is reverse (18).

The questionnaires were submitted to the college members, and after summarizing their comments, the necessary corrections were made.

To determine the validity of socio-demographic characteristics in this study, content and face validities were used. The questionnaire was given to the expert people on the subject and accordingly necessary corrections were made on it.

By performing a test on 20 women with high-risk sexual behaviors, reliability of the questionnaire was determined by Cronbach alpha coefficient. The Cronbach alpha for perceived social support and mental health questionnaires were calculated as 0.893 and 0.877 , respectively.
Data Analysis
The socio-demographic and social support data were analyzed using descriptive statistics consisting number, percentage, mean and standard deviation. The relationship between social support and mental health was evaluated by Pearson test. The relationship between 
mental health and socio-demographic data was evaluated by bivariate tests. The multivariate linear regression model (backward regression) was used for predicting the effect of independent variables (socio-demographic characteristics and social support) on the dependent variable (mental health), and controlling the effect of confounding variables.

\section{Results}

Of 149 subjects, $52.3 \%$ were above 35 years old. About two-thirds $(63.8 \%)$ of the women were housewives, and about half (40.3\%) were divorced. One-fourth $(25.5 \%)$ of the women had no children, and three-fourths (74.5\%) of them had 1 to 3 children. In terms of education, about half $(43.6 \%)$ of the women had elementary and secondary school educations, and about one quarter (25.5\%) of them were illiterate. About half (56.4\%) of the women stated that they themselves were the source of income and most (77.2\%) of them reported insufficient income. In terms of place of residence, less than one quarter $(17.4 \%)$ of them had no specific place to live in. One quarter $(25.5 \%)$ of women used drugs, and half of them used tobacco $(50.3 \%)$ and alcohol (53.2\%). A history of sexual abuse by relatives was reported in $12.1 \%$ of the participants. Majority (80.5\%) of the women had experienced spousal violence, and half (56.4\%) of them had experienced non-spousal violence. In terms of violence, these women had experienced physical, sexual, verbal, and emotional violence by their husbands $(55.0 \%)$ or others (30.2\%). Moreover, 20\% of the participants had one type of sexually transmitted infections, and $40 \%$ of them reported a history of nonsexual infections. Most (82.6\%) women reported the use of a condom (Table 1).

The total score of mental health in the women was 50.7 (18.2); the score ranged from 0-84. The best status belonged to the depression subscale [10.5 (7.1)] and the worst status belonged to the social dysfunction subscale [14.6 (4.5)]. The mean (SD) score for social support was 99.0 (27.3) from the score range of 25-175. Based on Pearson's test, there was a significant correlation between social support and mental health, physical condition, anxiety and social function disorder $(P<0.001)$ (Table 2$)$. The mental health was poor in $92 \%$ of the women with high-risk sexual behaviors (Figure 1).

The mean (SD) score for social support was 99.0 (27.3) from the score range of 25-175. Perceived social support in $80 \%$ of the women with high-risk sexual behaviors was low to moderate (Figure 2).

Based on bivariate tests, the variables of age, marital status, drug use, education, income adequacy, history of imprisonment, spousal violence, type of spousal violence, non- spousal violence, and type of non- spousal violence had a statistically significant relationship with mental health (Table 1). To determine the effect of independent variables (social support and socio-demographic characteristics) on the dependent variable (mental health),
Table 1. Sociodemographic Characteristics and Their Association With Mental Health in Women With High-Risk Sexual Behaviors in Tabriz City, Iran, 2017 ( $\mathrm{n}=149$ )

\begin{tabular}{|c|c|c|c|}
\hline Variable & No. (\%) & Mean (SD) & $P$ Value \\
\hline Age (y) & & $52.0(21.0)$ & 0.002 \\
\hline$<25$ & $25(16.8)$ & $41.3(20.0)$ & \\
\hline $25-35$ & 46 (30.9) & $56.6(18.5)$ & \\
\hline$>35$ & $78(52.3)$ & 50.3 (15.9) & \\
\hline Job status & & & 0.188 \\
\hline Unemployed & $47(31.5)$ & $46.8(18.1)$ & \\
\hline Employed & 7 (49.7) & 53.4 (19.9) & \\
\hline Housewife & $95(63.8)$ & $52.5(17.8)$ & \\
\hline Housing & & & 0.310 \\
\hline Personal & $98(65.8)$ & $51.4(18.2)$ & \\
\hline Parents' home & $25(16.8)$ & $53.2(19.3)$ & \\
\hline Other & $26(17.4)$ & $46.0(15.8)$ & \\
\hline Children & & & 0.142 \\
\hline 0 & $38(25.5)$ & $46.7(22.0)$ & \\
\hline $1-2$ & $75(50.3)$ & $50.8(16.6)$ & \\
\hline$\geq 3$ & $36(24.2)$ & $55.0(15.7)$ & \\
\hline Condom use & & & 0.737 \\
\hline Yes & $123(82.6)$ & $50.5(18.3)$ & \\
\hline No & $26(17.4)$ & $51.8(17.1)$ & \\
\hline Substance abuse & & & 0.001 \\
\hline Yes & $38(25.5)$ & $59.5(20.9)$ & \\
\hline No & $111(74.5)$ & $47.8(16.0)$ & \\
\hline Marital status & & & 0.041 \\
\hline Single & $22(14.8)$ & 41.2 (21.9) & \\
\hline Married & $58(38.9)$ & $53.5(18.1)$ & \\
\hline Divorced & $60(40.3)$ & $52.1(16.1)$ & \\
\hline Widow & $9(6.0)$ & $47.3(13.8)$ & \\
\hline Education level & & & 0.032 \\
\hline No education & $38(25.5)$ & 56.5 (17.9) & \\
\hline Primary or secondary school & $65(43.6)$ & $51.5(16.9)$ & \\
\hline High school or diploma & $32(21.5)$ & $45.0(17.0)$ & \\
\hline Higher education & $14(9.4)$ & $44.9(22.0)$ & \\
\hline Source of income & & & 0.745 \\
\hline Person herself & $84(56.4)$ & $49.8(16.1)$ & \\
\hline Family & $23(15.4)$ & $52.0(19.8)$ & \\
\hline Husband & $42(28.2)$ & $52.0(21.0)$ & \\
\hline Adequacy of income & & & 0.048 \\
\hline Sufficient & $7(4.7)$ & $45.0(14.0)$ & \\
\hline Fairly sufficient & $27(18.1)$ & $43.8(18.0)$ & \\
\hline Insufficiency & $115(77.2)$ & 52.7 (17.9) & \\
\hline Alcohol consumption & & & 0.165 \\
\hline Yes & $78(52.3)$ & $52.7(20.3)$ & \\
\hline No & $71(47.7)$ & 48.5 ( 14.9$)$ & \\
\hline Sexually abused by relatives & & & 0.759 \\
\hline Yes & $18(12.1)$ & $49.6(17.1)$ & \\
\hline No & 131 ( 87.9) & $50.9(18.2)$ & \\
\hline Tobacco consumption & & & 0.357 \\
\hline Yes & $75(50.3)$ & $52.1(20.2)$ & \\
\hline No & $74(49.7)$ & $49.4(15.6)$ & \\
\hline
\end{tabular}




\begin{tabular}{|c|c|c|c|}
\hline Variable & No. (\%) & Mean (SD) & $P$ Value \\
\hline Prison history & & & 0.001 \\
\hline Yes & $25(16.8)$ & $63.4(17.1)$ & \\
\hline No & $124(83.2)$ & $48.2(17.2)$ & \\
\hline Spousal violence & & & 0.001 \\
\hline Yes & $123(80.5)$ & $53.4(17.0)$ & \\
\hline No & $26(19.5)$ & $39.9(21.0)$ & \\
\hline Type of violence ${ }^{a}$ & & & 0.003 \\
\hline One type of violence & 41 (27.6) & 49.4 ( 9.4) & \\
\hline Several types of violence & $82(55.0)$ & $55.0(17.9)$ & \\
\hline Non-spousal violence & & & 0.014 \\
\hline Yes & $84(56.4)$ & $53.9(18.0)$ & \\
\hline No & $65(43.6)$ & $46.6(17.4)$ & \\
\hline Type of violence $^{b}$ & & & 0.009 \\
\hline One type of violence & $39(26.2)$ & $48.1(13.3)$ & \\
\hline Several types of violence & $45(30.2)$ & $58.5(20.5)$ & \\
\hline Genital diseases & & & 0.144 \\
\hline Sexual & $30(20.1)$ & $55.4(18.1)$ & \\
\hline Other infections & $62(41.6)$ & $47.7(14.6)$ & \\
\hline No disease & $57(38.3)$ & $51.6(20.9)$ & \\
\hline
\end{tabular}

Abbreviation: SD, Standard Deviation.

a Types of spousal violence: Verbal (6), Emotional (3), Sexual (7), and Physical (25).

b Types of non-spousal violence: Verbal (3), Emotional (16), Sexual (9), and Physical (11).

Table 2. Scores of Mental Health and Subscales and Relationship With Social Support in Women With High-Risk Sexual Behaviors in Tabriz City, Iran, 2017 ( $n=149)$

\begin{tabular}{lcc}
\hline Variables & Mean (SD) & $\boldsymbol{r}(\boldsymbol{P}$ Value $)$ \\
\hline Total mental health & $50.7(18.2)$ & $-0.549(<0.001)$ \\
Anxiety & $13.0(5.4)$ & $-0.464(<0.001)$ \\
Depression & $10.5(7.1)$ & $-0.511(<0.001)$ \\
Social function & $14.6(4.5)$ & $-0.327(<0.001)$ \\
Physical status & $12.5(5.4)$ & $-0.414(<0.001)$ \\
Social support & $99.0(27.3)$ & \\
\hline
\end{tabular}

Abbreviation: SD, Standard Deviation.

the variables of social support, age, occupation, children, substance use, marriage, education, income adequacy, alcohol use, imprisonment, spousal violence, type of spousal violence, non-spousal violence, type of nonspousal violence, and genital diseases were entered into the multivariate linear regression (backward regression). Variables of social support, substance use, and spousal violence remained in the model and had a significant correlation with mental health and were able to predict $35.4 \%$ of mental health variance in the women, to such a level that with increase of social support, the mental health status got better $(\beta=-0.3 ; 95 \% \mathrm{CI}=-0.4$ to -0.2$)$. In the women who had drug use, the mental health got worse $(\beta=6.7 ; 95 \% \mathrm{CI}=1.1$ to 12.2$)$ and in the women who had the experience of spousal violence, the mental health got

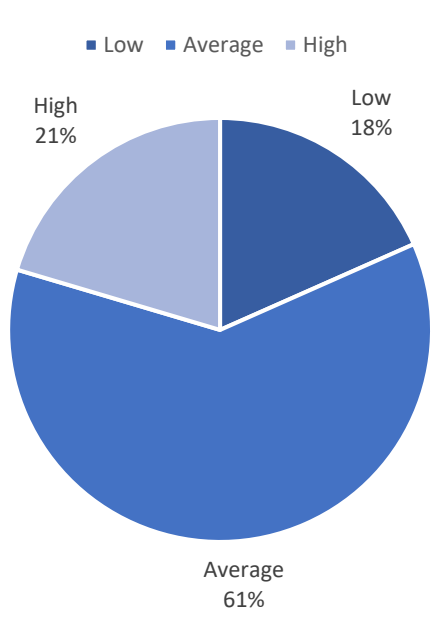

Figure 1. Social Support Levels

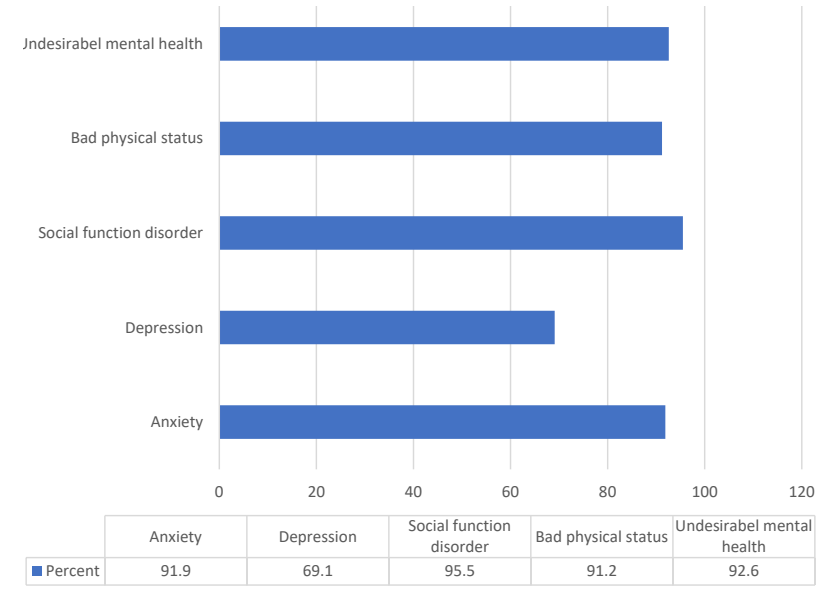

Figure 2. Mental Health and its Scales.

worse $(\beta=9.2 ; 95 \% C I=3.1$ to 15.0$)$ (Table 3$)$.

\section{Discussion}

The mental health and social support were examined in the women with high-risk sexual behaviors. Mental health was unsatisfactory in $92 \%$ of the women with high-risk sexual behaviors. The best status belonged to the depression subscale and the worst status belonged to the social dysfunction subscale. The variables of social support, drug use, and spousal violence were the predictors of mental health.

Polia et al investigated anxiety, depression, and drug use in the female sex workers. Anxiety and depression were reported as $78 \%$ and $80 \%$ in the female sex workers, respectively (19). The study of Patel et al showed that depression and anxiety were common in the female sex workers and severity of depression had a significant relationship with violence, disease, and income level (20). The results were consistent with those of the present study.

Romans et al compared physical and mental health in the female sex workers and the control group and found that there was no significant difference between the two 
Table 3. Predictors of Mental Health in Women With High-Risk Sexual Behaviors in Tabriz City, Iran, $2017(n=149)$

\begin{tabular}{lcc}
\hline Variable & $\boldsymbol{\beta}(\mathbf{9 5 \%} \mathrm{Cl})$ & $\boldsymbol{P}$ Value \\
\hline Social support & $-0.3(-0.4$ to -0.2$)$ & $<0.001$ \\
$\begin{array}{l}\text { Drug use (Reference: No) } \\
\quad \text { Yes }\end{array}$ & $6.7(1.1$ to 12.2$)$ & 0.01 \\
$\begin{array}{l}\text { Spousal violence (Reference: No) } \\
\quad \text { Yes }\end{array}$ & $9.2(3.1$ to 15$)$ & 0.003 \\
\hline
\end{tabular}

groups in terms of social functioning, and physical and mental health (21). Their results did not corroborate those of ours.

In the present study, $80 \%$ of the women with high-risk sexual behaviors had low and moderate social support. These results reflect the fact that in these women, unsafe sexual behaviors were affected by the level of social support they received. These findings were consistent with a review study by Qiao et al, who examined the relationship between social support and HIV risk behaviors reported. The social support was associated with HIV risk behaviors in sex workers. However, such results were not obtained for adolescents or people who had temporarily used an addictive drug and were exposed to AIDS-related risk behaviors (22).

The study of Rossler et al aimed to determine the mental health in the female sex workers. The results showed that the socioeconomic level of these women had a significant relationship with their mental health (23). The results of studies by Fatehi et al and Kalantari \& Roshanfekre showed that the causes of tendency of women to prostitution were lack of the family support, unemployment, drug use, imprisonment, and lack of shelter $(24,25)$. The results were consistent with those of the present study.

In the present study, $46 \%$ of the women were divorced or widow, and $77 \%$ had an insufficient income. The results were similar to Malakooti et al results, in which $46 \%$ of the women with multiple sex partners were divorced or widow, and their main reason for being a sex worker was unemployment and insufficient income (26). Fatehi et al also reported being divorced, lack of family support, and unemployment as the causes of women's inclination to prostitution (24).

In the present study, more than $50 \%$ of the women with multiple sex partners were illiterate or low-educated, and $9 \%$ of them had higher level of education, which shows that the lower education level led to a higher risk of sexual behaviors. These results were consistent with those of Fawole \& Dagunduro (27) and Coetzee et al (28), in that the education level had a significant relationship with HIV risk behaviors and violence.

In the present study, based on multivariate linear regression, variables of social support, drug use, and spousal violence had a statistically significant relationship with mental health and were able to predict $35.4 \%$ of variance of mental health in the women.
In this study, social support was a predictor of mental health in the women. Harandi et al evaluated the relationship of mental health with social support and found that social support had a moderate effect on mental health (0.356) (29). The stuady of Wang et al showed that stress-induced depression was lower in the persons with a social support compared to the control people (30). These results were consistent with the results of the present study.

In this study, drug use was a predictor of mental health in the women. The study by Amini-Lari et al showed that the psychosocial status in the female sex workers was worse than that in the control group, and also the drug use had a significant relationship with mental health (31). The study of Hengartner et al aimed at evaluating the mental health in the female sex workers. Their results showed that drug use had a significant relationship with the mental health in the women (32). The results were consistent with the results of the present study.

Furthermore, in this study, violence was one of the predictors of mental health in the women. Mendonça and Ludermir in a prospective cohort study used a selfreported mental health questionnaire for the women who enrolled in family health program and showed that mental health disorders were higher in the women with emotional violence and if they had physical and sexual violence, mental health got worse (33). The study of Meeker et al on determining the spousal violence and mental health in 10119 women showed that mental health was worse in the women with sexual abuse history and also mental health was similar in the women with physical or emotional violence (34). The results were consistent with those of the present study.

\section{Limitations and Suggestions}

As one limitation of this study, women possibly did not answer the questions or did not answer correctly for fear of legal issues. The participants were consulted in this regard and were assured about the confidentiality of their information and privacy in the study. The generalizability of the results is reduced due to convenience sampling method. Further studies with a similar subject and random sampling method are recommended.

\section{Conclusions}

The results showed that mental health was undesirable in the women who had high-risk sexual behaviors, drug use, spousal violence, and low social support. These factors can affect tendency of women to prostitution and high-risk sexual behaviors. Therefore, this group of women need to frequently visit DIC centers with appropriate strategies in order that they can recover their mental and physical health and reduce their tendency towards high-risk sexual behaviors for earning money. This, in turn, will enhance society health by the reduction of sexually transmitted diseases specifically HIV/AIDS. 


\section{Conflict of Interests}

Authors declare that they have no conflict of interests.

\section{Ethical Issues}

The ethical approval was obtained from the Ethics Committee of Tabriz University of Medical Sciences (Code of Ethics: IR.TBZMED.REC.1396.262). Written informed consent was also obtained from the participants.

\section{Financial Support}

None to be declared.

\section{Acknowledgments}

We thank all staff in drop-in centers who helped us in this study.

\section{References}

1. World Health Organization (WHO). Understanding and addressing violence against women: intimate partner violence. WHO; 2012.

2. Kaysen D, Resick PA, Wise D. Living in danger: the impact of chronic traumatization and the traumatic context on posttraumatic stress disorder. Trauma Violence Abuse. 2003;4(3):247-264. doi:10.1177/1524838003004003004

3. World Health Organization (WHO). Unsafe sex. In: Comparative Quantification of Health Risks. Geneva: WHO; 2002.

4. World Health Organization (WHO). Sexually transmitted infections (STIs). Geneva: WHO; 2016.

5. Rekart ML. Sex-work harm reduction. Lancet. 2005;366(9503):2123-2134.

6. Herrman H, Saxena S, Moodie R. Promoting mental health: concepts, emerging evidence, practice: a report of the World Health Organization, Department of Mental Health and Substance Abuse in collaboration with the Victorian Health Promotion Foundation and the University of Melbourne. Geneva: World Health Organization; 2005.

7. Kawachi I, Berkman LF. Social ties and mental health. J Urban Health. 2001;78(3):458-467. doi:10.1093/ jurban/78.3.458

8. Grav S, Hellzen O, Romild U, Stordal E. Association between social support and depression in the general population: the HUNT study, a cross-sectional survey. J Clin Nurs. 2012;21(1-2):111-120. doi:10.1111/j.13652702.2011.03868.x

9. Stevens E, Jason LA, Ram D, Light J. Investigating Social Support and Network Relationships in Substance Use Disorder Recovery. Subst Abus. 2015;36(4):396-399. doi:1 0.1080/08897077.2014.965870

10. Hiller SP, Syvertsen JL, Lozada R, Ojeda VD. Social support and recovery among Mexican female sex workers who inject drugs. J Subst Abuse Treat. 2013;45(1):44-54. doi:10.1016/j. jsat.2012.12.009

11. Chen G. Social support, spiritual program, and addiction recovery. Int J Offender Ther Comp Criminol. 2006;50(3):306-323. doi:10.1177/0306624x05279038

12. Toljamo M, Hentinen M. Adherence to self-care and social support. J Clin Nurs. 2001;10(5):618-627. doi:10.1046/ j.1365-2702.2001.00520.x

13. Baheiraei A, Mirghafourvand M, Mohammadi E,
Charandabi SM, Nedjat S. Social support for women of reproductive age and its predictors: a population-based study. BMC Womens Health. 2012;12:30. doi:10.1186/14726874-12-30

14. World Health Organization. HIV/AIDS. Geneva: WHO; 2017.

15. Islamic republic of Iran Aids progress Report. Unaids. http:// www.unaids.org/sites/default/files/country/documents/ IRN_narrative_report_2015.pdf. Published 2016.

16. Sahebi L, Vahidi R, Alihosseini S, Mousavi SH. Mental health status of intravenous drug addicts in drop in centers (DIC) of East Azarbaijan, north western part of Iran. Journal of Fundamentals of Mental Health. 2010;12(3):584595.

17. Weinert C, Brandt PA. Measuring social support with the Personal Resource Questionnaire. West J Nurs Res. 1987;9(4):589-602. doi:10.1177/019394598700900411

18. Goldberg DP, Hillier VF. A scaled version of the General Health Questionnaire. Psychol Med. 1979;9(1):139-145. doi:10.1017/S0033291700021644

19. Poliah V, Paruk S. Depression, anxiety symptoms and substance use amongst sex workers attending a nongovernmental organisation in KwaZulu-Natal, South Africa. S Afr Fam Pract. 2017;59(3):116-122. doi:10.1080/ 20786190.2016.1272247

20. Patel SK, Saggurti N, Pachauri S, Prabhakar P. Correlates of Mental Depression Among Female Sex Workers in Southern India. Asia Pac J Public Health. 2015;27(8):809819. doi:10.1177/1010539515601480

21. Romans SE, Potter K, Martin J, Herbison P. The mental and physical health of female sex workers: a comparative study. Aust N Z J Psychiatry. 2001;35(1):75-80. doi:10.1046/ j.1440-1614.2001.00857.x

22. Qiao S, Li X, Stanton B. Social support and HIV-related risk behaviors: a systematic review of the global literature. AIDS Behav. 2014;18(2):419-441. doi:10.1007/s10461-013-05616

23. Rossler W, Koch U, Lauber C, et al. The mental health of female sex workers. Acta Psychiatr Scand. 2010;122(2):143152. doi:10.1111/j.1600-0447.2009.01533.x

24. Fatehi A, Sadeghi S, Ekhlasi E. Description and analysis the sociology psychology properties of prostitutes and girls in Esfehan. Journal of Iranian Social Studies. 2010;4(2):66-80. [Persian].

25. Kalantari Ab, Roshanfekre P. The effects and consequences of divorce, systematic review of research conducted in Iran with an emphasis on gender considerations. The Journal of Qazvin University of Medical Sciences. 2011;9(3):111-11. [Persian].

26. Malakouti J, Mirghafourvand M, Farshbaf-Khalili A, Azadi T, Darabi B. Job motivation and its relationship with sexual attitude among Iranian sex workers. International Journal of Women's Health and Reproduction Sciences. 2016;4(4):194-199. doi:10.15296/ijwhr.2016.43

27. Fawole OI, Dagunduro AT. Prevalence and correlates of violence against female sex workers in Abuja, Nigeria. Afr Health Sci. 2014;14(2):299-313. doi:10.4314/ahs.v14i2.4

28. Coetzee J, Jewkes R, Gray GE. Cross-sectional study of female sex workers in Soweto, South Africa: Factors associated with HIV infection. PLoS One. 2017;12(10):e0184775. doi:10.1371/journal.pone.0184775

29. Harandi TF, Taghinasab MM, Nayeri TD. The correlation of 
social support with mental health: A meta-analysis. Electron Physician. 2017;9(9):5212-5222. doi:10.19082/5212

30. Wang X, Cai L, Qian J, Peng J. Social support moderates stress effects on depression. Int J Ment Health Syst. 2014;8(1):41. doi:10.1186/1752-4458-8-41

31. Amini-Lari M, Bagheri P, Ameli F. Mental health and HIVrelated high-risk behaviors among female sex workers. Shiraz E Med J. 2014;15(4):1-6. doi:10.17795/semj22326

32. Hengartner MP, Islam MN, Haker H, Rossler W. Mental Health and Functioning of Female Sex Workers in
Chittagong, Bangladesh. Front Psychiatry. 2015;6:176. doi:10.3389/fpsyt.2015.00176

33. Mendonca MFS, Ludermir AB. Intimate partner violence and incidence of common mental disorder. Rev Saude Publica. 2017;51:32. doi:10.1590/s15188787.2017051006912

34. Meekers D, Pallin SC, Hutchinson P. Intimate partner violence and mental health in Bolivia. BMC Womens Health. 2013;13:28. doi:10.1186/1472-6874-13-28

(c) 2019 The Author (s); This is an open-access article distributed under the terms of the Creative Commons Attribution License (http://creativecommons.org/licenses/by/4.0), which permits unrestricted use, distribution, and reproduction in any medium, provided the original work is properly cited. 